\title{
Educação, justiça e direitos humanos
}

Carlos Alberto Vilar Estêvão

Universidade do Minho

\section{Resumo}

Neste artigo, o autor reflecte sobre a questão da justiça e dos direitos humanos, tendo presente as exigências da democracia deliberativa, na linha de Habermas e, sobretudo, as propostas de uma democracia comunicativa.

Assim e num primeiro momento, o autor problematiza as relações entre democracia, justiça e direitos humanos, dando um particular realce quer às tendências individualistas e mercantilizadas de ver a democracia e os direitos quer às concepções deliberativa e comunicativa da democracia e suas implicações em termos de justiça e direitos humanos.

A partir daqui, a reflexão inflecte para o campo da educação, como um outro lugar da justiça, debatendo a questão da justiça escolar e a concepção da escola como organização dialógica e comunicativa, realçando, em linguagem habermasiana, as funcionalidades sistémica e comunicativa que a perpassam. 0 autor completa esse enquadramento destacando, dentro da ideia de que a escola é um lugar de vários mundos e de justiças, as múltiplas racionalidades mobilizadas pelos actores escolares, a quem compete fazer opções, conscientes de que, quando a racionalidade comunicativaemancipatória domina sobre outros tipos de racionalidade, a justiça e os direitos se abrem e se universalizam.

Finalmente, essa discussão é retomada no último ponto do artigo, mas agora enquadrada nos desafios da globalização entendida em vários sentidos, terminando com a referência, dentro de uma concepção de globalização contra-hegemónica, a uma "democracia cosmopolítica", favorecedora de uma cordialidade solidária e cosmocidadã, apoiada nos direitos humanos.

\section{Palavras-chave}

Educação - Justiça - Direitos humanos - Globalização.

\footnotetext{
Correspondência:

Carlos Alberto Vilar Estêvão

Instituto de Educação e Psicologia

Univ. do Minho - Campus de Gualtar

4700 - Braga - Portugal

e-mail: cestevao@iep.uminho.pt
} 


\title{
Education, justice, and human rights
}

Carlos Alberto Vilar Estêvão

Universidade do Minho

\begin{abstract}
In this article the author reflects on the issue of justice and human rights, considering the demands of a deliberative democracy, along the lines of Habermas and, above all, of the proposals of a communicative democracy.

Thus, at first, the author problematizes the relationships between democracy, justice, and human rights, giving special emphasis to the individualistic and merchantilized tendencies to see democracy and the rights, and to the deliberative and communicative conceptions of democracy, and their consequences in terms of justice and human rights.

From this point, the reflection veers towards the field of education as another locus of justice, debating the issue of school justice and the concept of the school as a dialogical and communicative organization, highlighting, in Habermasian terms, the systemic and communicative functionalities that permeate it. The author concludes this framework by stressing, within the idea that the school is a place of many worlds and justices, the multiples rationalities mobilized by the school agents, who should make their choices aware of the fact that, when the communicative-emancipative rationality predominates over other types of rationality, justice and rights open up and universalize.

Finally, this discussion is continued in the last part of the article, but now referred to the challenges of globalization understood in several senses, finishing with the reference, within a counter-hegemonic concept of globalization, to a "cosmopolitical democracy", supportive of a solidary and cosmo-citizenly cordiality based on the humans rights.
\end{abstract}

\section{Keywords}

Education - Justice - Human rights - Globalization.

Contact::

Carlos Alberto Vilar Estêvão

Instituto de Educação e Psicologia

Univ. do Minho - Campus de Gualtar

4700 - Braga - Portugal

e-mail: cestevao@iep.uminho.pt 
A justiça, independentemente das múltiplas interpretações de que tem sido alvo ao longo da história, parece ser uma aspiração de toda a humanidade. Nesse sentido, e para não recuar muito no tempo, também a Declaração Universal de Direitos Humanos de 1948 reafirma esse impulso universalista quando, no seu preâmbulo, diz que: “A liberdade, a justiça e a paz no mundo têm por base o reconhecimento da dignidade intrínseca e dos direitos iguais e inalienáveis de todos os membros da família humana".

Por outro lado, cada vez mais a humanidade parece sentir também que a linguagem dos direitos humanos é aquela que afirma, de um modo mais coerente, a "igualdade moral de todos os indivíduos", como afirma lgnatieff (2001, p. 111), reconhecendo, embora, que é uma linguagem que se produz num mundo de conflito, de argumentação, de deliberação.

Entretanto, e independentemente das polémicas em redor da fundamentação e da diversidade de objectivos que os direitos humanos podem servir, muitos países têm vindo a adoptar, nas suas constituições e noutras leis fundamentais relativas à educação, os princípios da Declaração Universal dos Direitos do Homem. Aliás, o direito constitucional tem vindo a impor-se como locus privilegiado de consolidação das pretensões democráticas de cidadania, embora se assista também em certos Estados à reinterpretação dos princípios constitucionais na linha da lógica mercadológica da política.

Interessa, por isso, repensar também a democracia em tempos de globalização, de modo a entretecer ainda mais as suas relações, ainda que complexas, com a justiça e os direitos humanos.

\section{Democracia, justiça e direitos humanos}

$\mathrm{Na}$ actual conjuntura do capitalismo flexível e transnacional, do "novo espírito do capitalismo", os direitos humanos, que consti- tuem uma parte intrínseca da democracia (desde logo, porque a garantia das liberdades básicas é uma condição necessária para que a voz das pessoas se torne efectiva nas questões públicas e para que o controlo popular sobre os governos fique assegurado [Beetham, 2003, p. 93]), confrontam-se com sérios desafios que resultam de novas propostas do papel do Estado e do mercado e de novas concepções de democracia.

Para simplificar, vou referir-me apenas a duas tendências que claramente influenciam as concepções e práticas de experienciação da justiça e dos direitos humanos, tendo consciência, no entanto, que a sua regulação social e política se concretiza frequentemente de múltiplas formas, de acordo com a configuração heterogénea que os Estados apresentam.

Assim, e na linha de Bobbio (2000), uma das duas vias principais para se conseguir apresentar os fundamentos teóricos da democracia moderna é precisamente (para além da filosofia utilitarista) a doutrina dos direitos do Homem. Isso significa que a democracia moderna é inconcebível sem referência aos direitos e à justiça, ainda que estes privilegiem, dentro de uma concepção individualista e atomista da sociedade, sobretudo a ideia de protecção, quer da propriedade quer do próprio ser dos indivíduos. Ou seja, a democracia moderna emerge intimamente conectada com os direitos individuais, avultando aí a liberdade entendida quer como "licitude" (reportada à ideia de permitido) quer como "autonomia" (referida ao poder de estabelecer normas a si próprio e de lhes obedecer) - e o direito da felicidade, pois na visão individualista ser justo corresponde a ser tratado de modo a poder satisfazer às suas necessidades e alcançar os seus próprios fins.

Esse filão individualista da democracia, mal-grado outras propostas alternativas que intentam dar-lhe um cariz mais igualitário e solidarista, tem vindo a ser, nos tempos que correm, revalorizada dentro de uma concepção de Estado que parece reforçar a substância ideológica do individualismo ao mesmo tempo que apoia a vi- 
são "libertária” (Lukes, 1998) dos direitos integrados num contexto de liberdade de mercado.

A "nova democracia”, ajustada a um Estado "oco" ou a um "quase-Estado", de pendor neoliberal, apresenta-se também como capaz de proteger a justiça e os direitos humanos, ainda que de uma forma algo paradoxal: por um lado, reconhece-se que é bom que se fale deles até para que os mecanismos de mercado possam funcionar bem e manter uma certa boa consciência; por outro lado, eles mantêm a marca individualista e conservadora (da ordem social vigente), deixando-se por exemplo cair o qualificativo "social" da justiça para se tornar numa justiça "neo-pietista" a favor dos desprotegidos (pobres e necessitados em vez de constituir um conjunto de direitos universais de cidadania), com o seu público preferencial (o público privado), com os seus actores privilegiados (os líderes empresariais que progressivamente vêem convertidos os seus interesses particulares em políticas públicas, apoiados pelo processo crescente de oligarquização do Estado em que os interesses privados e públicos se fundem).

Torna-se claro, portanto, que a actual concepção de mercado já não é a de mero mecanismo de alocação de recursos como era na sua concepção liberal inicial, mas é também uma instituição social inscrita num marco legal e moral, que deve ter presente, para funcionar melhor (ou de uma forma mais eficiente), a superioridade dos níveis de consciência social alcançado pela humanidade ou por certas sociedades acerca do que é justo. Contudo, também não é possivel esquecer que essa relegitimação do mercado não questiona a ideia de que "a legitimidade num contexto de mercado não deixa de ser mais uma mercadoria que pode ser comprada” (Beltrán Llavador, 2000, p. 23), enquadrada numa democracia que alguns apelidam de "pós-democracia" intimamente conectada com a comercialização da cidadania (Crouch, 2004) e com a construção das novas identidades baseada em novas oposições (por exemplo, aos funcionários públicos).

Independentemente das múltiplas formas que a democracia pode assumir e das relações complexas que podem ser estabelecidas entre ela e as diferentes classificações de direitos, considero que, pelas suas implicações profundas para a temática em análise, merece uma maior atenção a proposta de Bobbio ao entendê-la como "poder em público" (2000, p. 386), que pressupõe não apenas o combate a todas as formas de poder invisível, mas também a sua compreensão como uma forma superior de dialogação social que diz respeito a todos (bem comum) e que se decide entre todos na base da igualdade política.

Então, quanto mais o processo democrático potenciar a exposição e os debates públicos (ou seja, a "publicização"), tanto mais a "democratização da democracia” se sentirá; inversamente, quanto mais se perder o acesso ao público mais se residualizará a democracia, uma vez que tal pode equivaler à perda do acesso à igualdade e, portanto, à cidadania. Do mesmo modo, ainda, quanto mais se verificar a invasão do público pelo privado ou o abandono do postulado da proeminência do político, mais o público tenderá a banalizar-se, tal como nos alerta Arendt (apud Lafer,1999).

Um outro modo de ver a democracia e a própria política, concebida esta como uma prática de autodeterminação cidadã, coloca-as no interior do paradigma do diálogo, pelo que se torna relevante, nesse contexto teórico, aprofundar o modelo da democracia deliberativa na linha de Habermas (1999), que se reporta às pretensões que estão implicadas na comunicação humana e que se manifestam historicamente nas sociedades modernas racionalizadas.

Trata-se de uma concepção dialógica da política, entendida como um processo e razão e não exclusivamente de vontade, como um processo de persuasão argumentativa e não exclusivamente de poder, dirigido para a consecução de um acordo relativo a uma forma boa ou justa, ou pelo menos aceitável, de ordenar aqueles aspectos da vida que se referem às relações sociais e à natureza social das pessoas.

Essa acepção de democracia radica num ideal intuitivo de uma associação democrática cuja justificação assenta em argumentos públicos e racionais entre cidadãos iguais. $\mathrm{Ou}$ 
seja, quer as instituições quer as decisões só serão legítimas quando recebem a concordância dos implicados num procedimento democrático, em circunstâncias de participação livre e igual. Trata-se, insisto, de uma democracia como processo que cria um público, que discute o bem comum em vez de promover o bem privado de cada um, e cuja legitimidade deriva de todos os possíveis afectados pelas suas regulações as aceitarem como participantes em discursos racionais (Habermas, 1999).

Obviamente que esse tipo de democracia, pressupondo uma estrutura argumentativa da discussão pública, pressupõe a formação racional da vontade e da opinião públicas, segundo as exigências da racionalidade comunicativa. Na verdade, as práticas democráticas deliberativas exigem ir além do voto, mobilizando a capacidade de questionar e mudar as preferências pré-fixadas, próprias ou alheias, pela via da(s) razão(ões).

São, aliás, as "políticas discursivas" que, para Habermas, se tornam necessárias para ultrapassar e prevenir as crises de legitimação política. É, por conseguinte, o debate público, a situação ideal do discurso, que permite verificar se o resultado pode ser aceite como justo ou não pelos cidadãos. E, aqui, a lei, mais do que ser um modo de regular a competição (como é no liberalismo) ou uma expressão da solidariedade social (como acontece no republicanismo), deve visar a institucionalização das condições da comunicação deliberativa, pois só sob essas condições de comunicação é que emerge a produção legítima do direito, cabendo então aos direitos humanos, que possibilitam o exercício da soberania popular, um papel fundamental na satisfação da "exigência de institucionalização jurídica de uma prática cidadã do uso público das liberdades" (Habermas, 1999, p. 254). Caberá então ao Estado de direito institucionalizar apenas as formas de comunicação necessárias a uma formação racional da vontade.

Torna-se, por isso, fundamental, para Habermas, que as próprias comunicações políticas sejam filtradas deliberativamente, reconhe- cendo-se embora que elas dependem também dos recursos do mundo da vida - ou seja, "de uma cultura política livre e de uma socialização política de tipo ilustrado e, sobretudo, das iniciativas das associações conformadoras da opinião" (1999, p. 348) - que se constituem e regeneram espontaneamente.

Depois, e na medida em que a democracia deliberativa deve apenas propor princípios e procedimentos que garantam a fundação das normas, das convenções e das instituições na razão, o esforço de formação deve ir no sentido de procedimentalizar ou de "fluidificar comunicacionalmente" a soberania popular e de conceber o exercício do poder comunicacional (ancorado no mundo da vida e livre de dominação), segundo o modelo da ética da discussão, em que apenas opera a razão procedimental.

Independentemente de outras leituras, é justo frisar, tal como faz Cunningham (2001), que essa abordagem pretende ultrapassar o formalismo da democracia liberal e que foi desenhada para justificar políticas e valores não opressivos, para combater modelos de democracia baseados nos interesses e na visão privatizada do processo político. Pretende-se que a democracia seja agora um processo que crie um público ou cidadãos que se orientam pela discussão em redor do bem comum, que mobilizam a autenticidade nos procedimentos discursivos, que transformam as suas preferências de acordo com fins públicos e racionalmente argumentados, em diálogo aberto e livre de dominação. Por outras palavra, as políticas são adoptadas porque os cidadãos e os seus representantes determinam a sua rectidão depois de ouvirem e criticarem razões, pelo que a definição de bem comum não se afirma como independente daquilo que as próprias pessoas determinam que seja, de acordo com procedimentos deliberativos em que todos os implicados são tratados como iguais.

Essa abordagem tem, por conseguinte, o mérito de reforçar a ética da justiça e dos direitos, uma vez que destaca a questão da legitimação e a construção do consenso (é o objectivo da deliberação) sobre bens comuns, 
embora esse consenso nem sempre possa ser obtido, pois o que a democracia deliberativa exige é que as partes oponentes ofereçam e estejam abertas a razões e se respeitem mutuamente, ou seja, que mobilizem o seu poder comunicativo. Isso significa que se pode viver em discordância moral de um modo moralmente construtivo.

Também no caso dos direitos do homem, o seu reconhecimento e expressão (em forma de Declarações, por exemplo) necessitam, dentro da lógica dessa abordagem, de uma comunidade de justificação, de um espaço público de discussão e justificação. Seria aqui que assentaria a "fundamentação racional" dos direitos e não em qualquer essencialidade transcendente.

Não obstante aceitarem muitos desses pressupostos, outros autores (como Young, 1997, por exemplo) criticam também a concepção de democracia deliberativa porque frequentemente esta confina a deliberação efectiva aos fóruns legais em que os representantes das culturas e raças dominantes continuam a estar sobre-representados. É que embora as formas deliberativas devam expressar a razão universal pura, as normas de deliberação não são, de facto, culturalmente neutras e universais, para além de tenderem a privilegiar os bem educados, o discurso formal, os desapaixonados, os que detêm a capacidade de deliberação reflexiva sobre o que é bom para a sociedade. Dai que os apelos à construção de um bem comum e à unidade da discussão democrática pode simplesmente revelar-se como mais um mecanismo de exclusão, porque privilegia os grupos com mais privilégios simbólicos e materiais, acabando a definição de bem comum por ser dominada por esses mesmos grupos.

Depois, a esfera pública tende a apresentar-se como um locus de obtenção de acordos harmoniosos, não incluindo, por conseguinte, "contra-públicos subalternos" (como os movimentos sociais de oposição) ou não reconhecendo que as "normas de deliberação" envolvidas nas esferas da discussão pública são culturalmente específicas. Outros, ainda, criticam essa concepção porque o dissenso, o conflito sobre o que são bens comuns, embora irresolúveis, são essenciais às políticas democráticas (aliás, nem todos os problemas são resolúveis pela discussão, nomeadamente os que tomam a forma de soma zero, nem a atenção ao conflito de interesses pode ser desviada para falhas de comunicação). Finalmente, uma outra debilidade dessa concepção tem a ver com a menor atenção não só aos aspectos da diferença, mas também aos do desejo e da justiça afectiva.

Perante essas debilidades, Young (1997) prefere falar de uma outra concepção de democracia - a comunicativa - que recolhe muito da anterior, mas que a completa noutros sentidos. $\mathrm{Na}$ verdade, a abordagem anterior não acautela o facto de nem todos estarem na mesma situação de comunicação nem, além disso, o facto de o argumento não ser o único modo de comunicação política e de poder até expressar-se de muitos modos.

Então, a aceitação e respeito pelo $\mathrm{Ou}$ tro na sua singularidade (individual e social), a interdependência significante, a importância da emoção ou dos actos perlocutórios (retórica), o direito do Outro contar a sua história com a mesma autoridade e o mesmo valor do ponto de vista da situação comunicativa tornam-se elementos-chave da sua proposta de uma "democracia comunicativa", mais atenta à ética do cuidado assim como aos direitos humanos como expressão suprema do cuidado e da solidariedade para com o Outro.

$\mathrm{Na}$ democracia comunicativa, então, a interacção comunicativa não omite a diferenciação de sentidos que os actores atribuem aos problemas, aos interesses, às próprias coisas, ao bem comum, nem esquece as suas diferentes posições sociais. E é esse reconhecimento da diferença e do que não é comum que desafia a própria argumentação e que leva a invocar a justiça e a "reciprocidade assimétrica" entre perspectivas dos sujeitos, uma vez que cada um tem a sua história que "transcende a copresença 
de sujeitos em comunicação" e cada posição social é estruturada pela configuração de relações entre outras posições, o que dá a cada locação um sentido específico e irreversível (Young, 1997, p. 52).

Por outro lado, essa concepção de democracia permite dar maior solidez à possibilidade de todos sermos vistos e ouvidos num espaço público, de articularmos colectivamente a voz no debate público, tendo em conta, porém, as nossas diferenças. Essa comunicação entre perspectivas diferentes preserva a pluralidade, a qual, segundo Young (1997) e invocando Arendt, deve ser compreendida como uma condição de publicidade. Além disso, dá um carácter contingente e parcial ao meu ponto de vista, ao mesmo tempo que reconhece aos outros o direito de desafiarem os meus argumentos e interesses, forçando-me a transformar as minhas expressões de auto-interesse pelos apelos à justiça. Desse modo, todos os participantes ganham uma visão mais ampliada dos processos sociais e simultaneamente se reforça a importância da regulação comunitária e cidadã.

E aqui voltaria a uma questão cara a certas feministas e que tem a ver com a possibilidade de a democracia comunicativa dar uma atenção particular à ética do cuidado, encarada esta sobretudo como um enquadramento moral das políticas sociais. Na verdade, o ideal da teoria comunicativa implica a atenção a aspectos não linguísticos da comunicação e, de uma forma geral, a outras formas de uma ética do cuidado que a democracia deliberativa, pela sua preocupação de ser uma democracia racional, omitia, desprezando, por essa mesma via, o carácter situado da comunicação e a sua ligação ao desejo.

Então, a ética do cuidado, mais atenta às peculiaridades e às relações no desenvolvimento moral, parece vir complementar a ética da justiça e, nesse sentido, vem reforçar a relevância da democracia comunicativa. Acrescente-se, no entanto, que esse facto não impede, de modo nenhum, as pretensões de universalização, dado que esta, do meu ponto de vista, é sobretudo uma característica das justificações morais e não exclui os juízos situados (Strike, 2002a). Penso, além disso, que a ética do cuidado, por enfatizar o lado da justiça afectiva (embora não tanto as estruturas sociais de poder), fomenta numa democracia comunicativa o que poderia chamar-se de uma "justiça reconstituinte" (Knopp apud Chamberlain; Houston, 2002, p. 183), para além de nos ajudar a perceber que os direitos se baseiam fundamentalmente em processos de comunicação e concessão de significado e que se constituem em verdadeiras ferramentas do diálogo que ajudam a interpretar e a reinterpretar as relações mútuas entre os membros de uma dada sociedade.

Considero, pois, que uma democracia comunicativa, não obstante também as suas debilidades (há que ter em conta que a política não é unicamente uma actividade deliberativa e comunicativa, mas ela é também estratégica), favorece uma visão mais completa da própria justiça de tal modo que esta, pensada sem o cuidado, se "converte mais num defeito que numa virtude" (Strike, 2002b, p. 202). Do mesmo modo, a democracia comunicativa pode vir a dar uma outra extensão à própria noção de espaço público, que surge então não apenas como fundado na argumentação intersubjectiva mas também na "partilha da sensibilidade".

\section{Educação, justiça e direitos humanos}

A partir das análises anteriores, a reflexão agora passa pela educação como um dos lugares naturais de aplicação, consolidação e expansão dos direitos humanos; como um direito-chave cuja negação é especialmente perigosa para o princípio democrático da igualdade civil e política; como uma arena de direitos e com direitos; enfim, como um outro nome da justiça.

Embora a educação tenha vindo, na actual conjuntura do capitalismo flexível e transnacional, a confrontar-se com sérios desafios que resultam de novas ideologias ou de novas concepções do papel do Estado - o qual mantém, apesar do seu aparente debilitamento (sobretudo da sua capaci- 
dade de respeitar os direitos), a substância ideológica do individualismo ao mesmo tempo que reforça a visão "libertária" dos direitos -, ela não pode alhear-se da sua contribuição para a criação de espaços públicos mais democráticos, para a dialogação pública, para a potenciação da "voz", para a aprendizagem das diversas formas por meio das quais os direitos humanos podem ser negados, omitidos ou promovidos.

Então, e não obstante essas vicissitudes, a educação, ela própria pertencente à segunda geração dos direitos económicos e sociais, não pode ficar indiferente aos valores e à "formação de uma cultura de respeito à dignidade humana mediante a promoção e a vivência dos valores da liberdade, da justiça, da igualdade, da solidariedade, da cooperação, da tolerância e da paz" (Benevides, 2003, p. 309).

Congruentemente com esses valores, a escola terá de ser reconsiderada como uma organização democrática, que normativamente se afirma como uma organização dialógica ou como “organização comunicativa” (Botler, 2004), assente num diálogo visando acordos que só serão justos se respeitarem certos princípios, quais sejam: o princípio da sinceridade; da inclusão ou da participação de todos os afectados no diálogo; da reciprocidade, que tem a ver com a igualdade de oportunidades; e da simetria, em que os interesses têm de ser considerados do mesmo modo e abertos à revisão argumentativa (GarcíaMarzá, 2002, p. 262).

Nesse sentido, a comunicação assim como o conflito tornam-se condições de possibilidade da escola como espaço público, ou seja, como espaço de debate, de convivialidade e de "voz", de intercâmbio de ideias, de direitos e deveres argumentativos, de adopção colectiva das decisões que ultrapassam os muros domésticos da própria escola, de democracia. Assim, quando a escola transige com a imposição de significados aos actos e suprime a possibilidade de discutir assuntos públicos, está claramente a impedir a interlocução e a impedir o direito à participação e, por isso mesmo, "a atentar contra a sua própria identida- de democrática” (Beltrán Llavador, 2000, p. 87). É que, ainda segundo esste autor, se a política é uma emanação do espaço público, esse, por sua vez, "não é possível sem uma determinada política, isto é, sem uma determinada forma de gestão dos assuntos que afectam a colectividade” (p. 88). Para tal, é necessária a comunicação que "faz" política na medida em que permite exprimir o conflito, mas também frequentemente gerá-lo. Nesse sentido, a escola como lugar de vários sentidos e de relações inscritas em práticas, que são também discursivas, exige a comunicação que, por sua vez, produz a escola porque recria o vínculo entre quem a integra.

Não obstante esse cenário, é possível destacar na escola a interferência de duas funcionalidades que convêm não omitir do ponto de vista da análise da escola como organização comunicativa. Uma dessas funcionalidades resulta da escola "como sistema", condicionadora ou colonizadora da acção pelos imperativos do Poder e da Economia. Dentro dessa lógica, a comunicação tende a "tecnologizar-se", como meio manipulável pelos desígnios sistémicos, servindo propósitos meramente instrumentais e hierárquicos, ao mesmo tempo que despreza e deslegitima outras formas de comunicação mais sintonizadas com os mundos de vida societais e das quais decorre verdadeiramente a natureza política da organização escolar (embora não se possa negar que a organização hierarquizada também contribui para modelar uma política).

Nesse verdadeiro transcendentalismo sistémico que coloniza a escola, o actor escolar deve sobretudo cumprir as suas funções predeterminadas em que as subjectividades pouco importam.

Quanto à segunda funcionalidade, relativa ao mundo de vida, as acções se coordenam por meio de interacções comunicativas estabelecidas entre os seus membros, isto é, apela-se a uma racionalidade comunicativa e emancipatória da acção educativa, com componentes éticos, e que permite a reconstrução crítica de situações sociais e a construção de uma civilidade escolar cidadã.

Temos então que, segundo a visão aqui proposta, as acções escolares podem ser analisa- 
das de acordo preferencialmente com uma razão mais instrumental (como seria o caso de acções que têm um carácter burocrático ou as acções de planificação económica, cumprindo a função de integração funcional da organização) ou com uma racionalidade de natureza prático-moral, esta última permitindo fundamentar os esquemas interpretativos baseados nos processos comunicativos escolares, ou seja, permitindo fundamentar as acções ocorridas nas interacções, visando um acordo sem coacção e em que as decisões adoptadas são apoiadas em argumentos racionais que cumprem as três pretensões de validade do discurso (verdade, correcção e veracidade).

Conjuga-se assim na escola, desde uma perspectiva macrossocial, uma dupla racionalidade, ao mesmo tempo que, numa perspectiva microssocial, se torna mais nítida a mobilização de vários tipos de racionalidade (instrumental, comunicativa e potencialmente comunicativa ou educativa) que impregnam as acções quotidianas da escola e a lógica argumentativa. Logo, não é possível compreender o significado da acções escolares sem o recurso à relação estabelecida pelos seus membros entre os eixos do sistema e do mundo de vida (Sabirón, 1999).

Essa focalização é congruente com o facto de a acção racional, visando os fins, estar intimamente ligada ao conceito de interacção simbolicamente mediada, "pelo que nas acções de natureza instrumental surgem sempre aspectos relativos ao mundo da vida prático-moral, já que a sociedade se reproduz sobre esta dupla via (reprodução material-reprodução simbólica) mas totalmente integrada uma na outra" (Gimeno, 1995, p. 473). Ou seja, as próprias interpretações simbólicas e culturalistas podem não passar de formas de "concretização e definição das funções sistémicas em cada 'mundo de vida' escolar” (Sabirón, 1999, p. 57).

Não obstante a riqueza dessa contextualização teórica, considero que é possível completá-la com outras especificações ao nível das racionalidades mobilizadas e que se exprimem no polimorfismo regulatório quer da acção social, em geral, quer da acção escolar, em particular.
Por outras palavras, na medida em que é possível afirmar a existência de vários referenciais ou princípios reguladores da acção social e acção pública, uns apontando para aspectos mais burocráticos, outros mais modernizadores ou empresarialistas, outros mais mercantis ou neoliberais, outros ainda mais cidadãos e críticos, do mesmo modo é possível dizer que a escola, como organização, é também atravessada por vários princípios reguladores ou várias racionalidades que se vão metamorfoseando. É nesse sentido que tenho vindo a defender, na linha de Derouet (1992), a metaforização da escola como "um lugar de vários mundos" ou "universos de justificação múltipla”, reconhecendo embora que a natureza dos contextos políticos condiciona a hegemonia de uma determinada ordem de regulação escolar face às restantes (Estêvão, 2004).

Torna-se para mim evidente que esses vários princípios de regulação e suas racionalidades tendem a acentuar sobretudo o "pilar da regulação" (a escola como "acção comunicativa" tende a ser reprodutora na medida em que a acção comunicativa, desenvolvida sobre processos orientados para o entendimento, é uma categoria fundamental de reprodução simbólica das ordens estruturais da sociedade e de integração social dos indivíduos), embora o princípio crítico e cidadão tenha também potencialidades emancipatórias pelo realce dado à racionalidade comunicativa, à escola como comunidade de projectos e contexto de trabalho inter e intraprofissional, com uma cultura democrática materializada em estruturas de relação e de decisão, favorecedora de fórmulas mais densas e substantivas de justiça e dos direitos.

$\mathrm{Na}$ verdade, quando a racionalidade comunicativa-emancipatória domina sobre outros tipos de racionalidade (instrumental por exemplo, orientada para a eficácia), a justiça e os direitos abrem-se ou universalizam-se, permitindo à escola preparar os cidadãos para participarem na esfera da argumentação, da racionalidade ético-comunicativa, mas também para se abrirem à heterogeneidade cultural e à 
potenciação da comunicação dialógica entre as próprias culturas, favorecendo a interpretação, concebendo o conhecimento fundamentalmente como diálogo de intersubjectividades, reconhecendo as subjectividades definidas sobretudo como cruzamentos de relações num espaço que não é privado, fomentando a interlocução pública com a participação de todos no uso da sua voz, ajuizando, enfim, todas as acções educativas a partir dos critérios de verdade, da rectidão e da autenticidade.

Essa atitude dialógica que a educação deve fomentar significa, entre outros aspectos, o reconhecimento dos outros como interlocutores válidos, com direito a expressarem os seus interesses e a defendê-los com argumentos; o desenvolvimento da capacidade de participação num colectivo plural; o desenvolvimento de uma consciência crítica e tolerante; a preocupação por encontrar uma solução correcta e, portanto, entender-se com o interlocutor; perseguir metas conjuntas construídas pelos implicados e dirigidas ao entendimento; a procura de uma decisão final que expresse interesses universalizáveis (Cortina, 1999).

Considero, desse modo, que a noção de "justiça escolar" (e do direito em que assenta) não pode deixar de ser questionada, ainda que ela se apoie numa visão "universal" oficial. Na verdade, se a multiplicidade e poliformia dos princípios regulatórios da acção social são evidentes, torna-se lógicamente defensável a afirmação de uma dialectologia da justiça e dos direitos na "ordem escolar", embora esta nem sempre seja muito visível devido à hegemonia e dominação da justiça oficial (Estêvão, 2002a).

Nesse sentido, a normatividade dominante na escola não pode deixar de ser analiticamente problematizada, ainda que, no seu seio, se ocultem também "promessas" de emancipação e se propiciem práticas "universalizadas" de juridicidade e de justiça.

E é assim que ganha relevância teórica, entre outras, a questão da "justiça complexa" em educação confrontada com a teoria dos diversos capitais de Bourdieu, uma vez que a escola recebe "não-pessoas" cujo reconhecimento público advirá pela capacidade de estas absorverem o conhecimento oficial e de o reproduzirem.

Então, se tivermos presente as funções de reprodução e de legitimação das desigualdades sociais que a escola cumpre - nomeadamente pela transmissão de uma cultura imposta como legítima, isto é, portadora de um discurso socialmente neutro, universal e não arbitrário, portanto, indiferente à distribuição do poder na sociedade -, será aí que a delimitação da pertinência do conceito de justiça escolar deverá ter lugar.

De facto, e na medida em que, segundo Bourdieu (1966, 1998), a cultura escolar como cultura dominante dissimulada e naturalizada trata formalmente de modo igual, em direitos e deveres, quem é diferente, exigindo dos alunos qualidades que são desigualmente distribuídas entre as classes sociais, designadamente o capital cultural e o relacionamento com a cultura e o saber, também a justiça escolar (e educativa) se assume como naturalmente universal, tratando os seus actores como iguais em direitos e deveres, indiferente ao facto de, por esse processo e a coberto de uma relação formalmente igualitária, estar a sancionar as desigualdades iniciais dos alunos face à cultura dominante, fazendo da comunicação pedagógica, por exemplo, um campo de análise imprescindível para se captar a "violência simbólica" exercida sobre os alunos culturalmente não identificados com as definições da cultura dominante e sua justiça.

Torna-se claro então que a justiça, sob a forma de equidade formal e universal (e que tende a definir-se obedecendo ao critério de cada um receber de acordo com a sua contribuição) que a escola apregoa e distribui, reproduz de facto, embora de forma velada, uma pluralidade de formas de injustiça, situação que se agrava na medida em que a escola possibilita a acumulação e convertibilidade das diferentes formas de capital (nomeadamente pela conversão do capital socioeconómico em capital cultural sob a bandeira do mérito). 
Mais, esse reconhecimento da pluralidade de formas de capital, do seu funcionamento e das implicações em termos de desigualdades na escola reforça, do meu ponto de vista, a problematização da justiça como complexa, possibilitando-me, também por essa via, falar em novas formas ou configurações de justiça, as quais variam no seu poder de harmonização, atracção ou resistência relativamente à juridicidade dominante ou oficial (desde logo porque a posse e distribuição dos diferentes capitais, assim como os critérios distributivos para que remetem, são diferentemente valorizados pelo habitus da escola e da justiça escolar).

Em sintese, considerando que as desigualdades no mundo de hoje são múltiplas e decorrentes de relações de classe específicas que se estabelecem em vários mundos, haverá que contar então com registos de dominação (e, acrescentaria, de justiça) não homogéneos, ideia que a teoria dos capitais de Bourdieu acaba por corroborar ao distinguir várias espécies de capital, ou seja, vários poderes que definem as probabilidades de ganho num campo determinado (nesse caso, na educação) e que contribuem para determinar depois a posição no espaço social (Bourdieu, 1989).

Independentemente de outras consequências, essa perspectivação da educação e particularmente da escola dá, por um lado, um cariz contingente à sua ordem interna e à cultura escolar e, por outro, realça não só a disputa entre vários arbitrários, mas também o facto de as estratégias de acção no interior da escola terem muito a ver com o volume e os tipos de capital (económico, social, cultural, simbólico...) que são diferentemente valorizados, consoante o predomínio dos diversos mundos e justiças que estruturam a escola.

A educação e a escola como organização comunicativa não podem, pois, ficar indiferentes à dialogicidade interna que mobiliza diferentes vozes e argumentações (dialogicidade que compreende, pois, a intersubjectividade como mecanismo base da construção da pessoa como sujeito social no interior de uma comunidade de comunicação), assim como à dialec- ticidade que as confrontam com a universalidade da justiça, da igualdade e dos direitos face ao paradigma da diferença e da pluralidade.

\section{Educação, justiça e direitos humanos na era da globalização}

A dialecticidade atrás referida está a tornar-se cada vez mais visível nos tempos actuais de globalização.

Embora esta possa definir-se de vários modos (Estêvão, 2002b), ou seja, como um fenómeno multifacetado e multinível, o que pretendo acentuar aqui é que, embora eu me atenha sobretudo à sua vertente económica, na versão neoliberal, ela deve ser encarada também nas formas alternativas "contra-hegemónicas" e em que a educação pode deter um papel importante na sua activação.

Assim, a globalização, sobretudo se entendida, de acordo com a distinção de Folk, como "vindo de cima" (ou seja, vinda da coligação entre nações dominantes e de forças de mercado transnacionais), não potencia necessariamente uma cultura democrática e mais igualitária, uma vez que ela tende a ser sobredeterminada pela ideologia do neoliberalismo ou da "globalização competitiva" (Arruda, 2000), que intenta concretizar também como forma de racionalidade ligada à governamentalidade (em sentido Foucaultiano), uma espécie de neofeudalismo, com centros de poder sobrepostos e lealdades entrecruzadas, para além de tender a impor, ao nivel dos valores, a sua unidade e homogeneização. Nesse sentido, ela é sobretudo uma força corrosiva, capaz de dissolver a topografia convencional dos Estados, a interacção comunicativa, a atenção aos direitos humanos e à justiça, criando novas divisões (a divisão digital, por exemplo), novas fronteiras (centro-periferia, norte-sul, por exemplo), novos centros e novas margens, novas formas de poder e de controlo, novos apartheids sociais.

Contudo, a globalização representa também, ainda segundo Arruda (2000, p. 51), “um 
progresso na história humana." Se ela se orientar pela globalização "vinda de baixo", isto é, pela globalização da consciência humana e pela globalização cooperativa e solidária, valorizadora da diferença e diversidade, da tensão e da contradição, denunciadora do imperialismo cultural e dos seus efeitos descaracterizadores, torna-se de facto num progresso para a espiritualização ou eticização do mundo e das organizações, podendo aspirar-se então a uma democracia global que assente num outro contrato social, noutras redes de intercooperação, noutras estruturas de regulação, noutros códigos de conduta de agentes e nações, noutro sistema de justiça, noutro estatuto de direito e deveres de cidadania global (Arruda, 2000).

E é assim que, a outro nível, a globalização, embora lance um repto à justificabilidade do Estado-Providência, tal não significa que ela vá pôr em questão a sobrevivência desse mesmo Estado, embora o coloque, como dizem Fitoussi; Rosanvallon (1997, p. 98), perante um desafio sério, designadamente em termos da sua "capacidade de acompanhamento da transformação social”. Contudo, não deixa de ser verdade que o Estado actual se está transformando, como já referi, num "quase-Estado", tendendo quer para uma certa desnacionalização e executivização (por governos reféns de lógicas mercadológicas e/ou empresarialistas) que o enfraquecem na luta pelos direitos, quer para a oligarquização (em que os interesses públicos e privados tendem incestuosamente a contaminarse e a fundir-se). Isso significa que o Estado, nos tempos de globalização, e na medida em que mantém áreas de influência importantes e mecanismos apreciáveis de governança, de regulação, de segurança, de responsabilização, se posiciona de uma forma ambígua no que aos direitos humanos diz respeito. Na verdade, e como afirma Gready, o Estado, por um lado, "propicia a possibilidade dos direitos humanos, por outro, e como consequência directa, a sua impossibilidade universal" (2004, p. 351).

Por conseguinte, é necessário atender, na discussão sobre a bondade ou maldade da globalização na sua relação com a democracia e a justiça, ao facto de que nem toda a origem dos males está na globalização, podendo ter a ver antes, por exemplo, com a inadequação das actuais estruturas de regulação num contexto global ou com políticas públicas inadequadas. Além disso, como processo, a globalização parece obedecer a padrões de interconexão e de diferenciação dentro de uma dinâmica complexa que, ao nível dos direitos humanos, pode repercutir-se com regressões e providências minimalistas e residuais, mas também com progressos e novas solidariedades.

Consequentemente, e insisto neste aspecto, a globalização não pode ser lida de modo nenhum, como nos adverte Habermas (2000), segundo um qualquer parti pris apoiado exclusivamente na ortodoxia neoliberal e sua ideologia. Porém, também não se pode ser ingénuo desconhecendo a grande sobredeterminação da globalização pela ideologia e práticas neoliberais, situação que pode tornar-se mais preocupante quando as nossas sociedades, no dizer dos já citados Fitoussi; Rosanvallon, "são particularmente vulneráveis ao choque da mundialização porque são atravessadas por novas fragilidades e marcadas por formas igualmente novas de desigualdade" (1997, p. 3). E, nesse sentido, os efeitos negativos da globalização nos direitos humanos estão estruturalmente embebidos no sistema, centrifugando ou atirando para outro lugar (a heterotopia) os grupos sociais (e Estados) economicamente irrelevantes, em nome da nobre causa do crescimento económico e da competitividade global.

As implicações de tudo isso para a educação e para o sistema educativo são evidentes, pelo que não podem ficar de modo nenhum alheios a essa dinâmica global ou meter a cabeça debaixo da areia face às realidades do mercado global; não podem deixar de questionar a "prosperidade patalógica" do boom consumista a que vimos assistindo; simultaneamente, não podem render-se ao processo de mercantilização global, ficando indiferentes, por exemplo, à monetarização dos mundos vividos locais e às novas geografias de 
injustiça resultantes de um capitalismo multipolar sujeito a movimentos das suas "placas tectónicas" de impacto nem sempre previsível.

E um desses impactos pode situar-se precisamente ao nível da invasão das formas de colonização das organizações (empresariais, mas não só), pois, e tal como afirma Parker, depois de a globalização ter estabelecido a sua legitimidade na esfera económica, está agora “a mover-se para a colonização das esferas políticas e sociais" (2002, p. 49), mobilizando outros recursos, outros conceitos. Por exemplo, na área organizacional,

\section{[...] empowerment, humanização, democratiza-} ção, etc., tornaram-se buzzwords que reflectem a tentativa de transformar as organizações empresariais em monarcas legítimos da nova ordem mundial. (p. 55)

Depois, a própria insistência nos valores da lealdade à organização entendida esta como uma grande família ou comunidade, dentro da arquitectura simbólica do "novo espírito do capitalismo" de que falam Boltanski; Chiapello (1999), pode equivaler a uma reemergência de relações neofeudais em que a remercantilização do "novo emocionalismo" acaba por atravessar as relações contratuais e impor uma outra noção de justiça e até dos direitos do trabalhador.

Esse aspecto é deveras importante porque nos alerta para a possibilidade de a própria justiça e os direitos humanos, ao globalizar-se, poderem "mercantilizar-se" também, colocandose ao serviço apenas do benefício mútuo ou do livre jogo dos mercados financeiros internacionais, ou até constituir-se numa ideologia que acaba por legitimar a globalização neoliberal, desde logo pelo carinho especial dado aos valores civis e políticos em detrimento dos da igualdade e segurança económica, possibilitando, desse modo, uma noção dividida dos direitos humanos que leva à defesa exclusiva, como parece ser a moda actual das liberdades civis, não se considerando violação dos direitos huma- nos a deterioração dos direitos socioeconómicos. Como consequência disso, podemos estar a assistir, como afirma Shiva, (2004) à destruição quer dos direitos socioeconómicos quer até das liberdades civis.

Por outras palavras, a globalização dos direitos humanos pode esconder a realidade de ela globalizar, isso sim, os direitos das empresas (cada vez mais totais) acima dos direitos dos Estados e dos cidadãos, não levando em consideração os indivíduos como verdadeiros cidadãos por estes não contribuírem para a economia de mercado quer como produtores quer como consumidores (George, 2004), porque o que verdadeiramente conta agora é o homem como entrepreneur e que é capaz de mobilizar os seus conhecimentos e capacidades informais - ou, em termos de Bourdieu, o seu habitus para descodificar e usar formas mercadorizadas em seu próprio benefício, seja na educação ou em qualquer outra área social.

Será numa linha contra-hegemónica de globalização, em que os direitos humanos se constituem num dos seus elementos essenciais, que a minha proposta de uma democracia comunicativa ganhará novo alcance, acentuando uma nova característica (que trazia implícita): ela será também caracterizada como cosmopolita, ou melhor, como "cosmopolítica", realçando o desenvolvimento pluralista e interdependente da sociedade global, o respeito pela nova arquitectura civilizacional assente na diversidade das culturas e de objectivos, a "participação democrática multifacetada", a "política emancipatória" ligada a "política da vida ou de auto-realização", de que fala Giddens (1995, p. 129), mas sem nunca esquecer que "nas condições actuais do capitalismo global em que vivemos não há reconhecimento efectivo da diferença (racial, sexual, étnica, religiosa etc.) sem redistribuição social" (Santos, 2004, p. 26).

A democracia comunicativa deverá, ainda, implicar a dimensão universal da justiça e dos direitos inspiradores de um "código ético mínimo" ou de uma plataforma igualitária que respeite uma breve lista de direitos humanos 
em torno dos quais podemos conseguir acordo e que inclui os direitos civis e políticos e os direitos sociais, económicos e culturais de carácter fundamental, possibilitando, desse modo, a construção da "cosmocidadania", orientada para as questões planetárias.

Todavia, essa construção de uma plataforma mínima deve resultar de um esforço dialógico para construir o acordo na conversação entre distintos lugares, como nos propõe Appiah (2004, p. 216), criando-se assim uma universalidade ética que vem de baixo, que pressupõe o trabalho de tradução e a "hermenêutica diatópica”, e que é potenciadora do aparecimento de uma esfera pública global. E neste ponto, também Santos (2004, p. 40) parece concordar, ainda que discorde da existência de uma ética universal ou de um universalismo dos direitos humanos muito distintamente ocidental nos seus pressupostos. De facto, se ele concorda que "o cosmopolitismo [subalterno] dos oprimidos só pode resultar de uma conversa da humanidade" e que só "uma concepção multicultural dos direitos humanos assente na aprendizagem de que a defesa da dignidade humana tem vários nomes e nem todos nos são familiares”, então a finalidade é a mesma, embora os caminhos do cosmopolitismo emancipatório sejam outros.

Por outro lado, o "cosmopolitismo cordial" a que esse mesmo autor se refere, realça a importância da dialogicidade, o que nos leva a partir da ideia de que a nossa identidade está constituída dialogicamente, de que é moldada pelo diálogo e nesse sentido é intercultural. É por isso que os direitos humanos são originalmente, como diz Levinas (1989, p. 45), os direitos do outro homem, ou seja, implicam alteridade e é no seu exercício e propiciando o seu exercício aos outros que nos tornamos verdadeiramente democratas. Favorecedora dessa dialogicidade, a educação, como educação crítica, erige-se como uma via privilegiada para a construção da democracia comunicativa, facilitando o reconhecimento do facto de cada cultura ser potencialmente todas as outras, obrigando à celebração da raiz humana comum que se revela pela diversidade, exigindo o reconhecimento dos outros como interlocutores válidos, com direito a expressarem os seus interesses e a defendê-los com argumentos, procurando uma decisão final que expresse interesses universalizáveis na linha do reforço da agência humana e do direito a relações humanas dignas, solidárias e justas.

Essa intenção de universalização favorecida pela educação faz da escola, como organização comunicativa ou como "esfera pública democrática”, um verdadeiro fórum público ou um espaço público que dá a possibilidade de ser visto e ouvido (ou seja, na linha de Arendt, 2001, como "espaço de aparição"), que transforma os seus actores em autores ou sujeitos de direito, empenhados numa ética pública a que todos devem ter acesso, porque esse acesso ao público e ao uso público da razão, em termos kantianos, é uma condição de cidadanização e um sinal da pujança de uma democracia verdadeiramente deliberativa e comunicativa.

Então, uma educação democrática deve assumir-se como não neutral, apresentando-se, ela própria, como uma educação detentora de direitos humanos, garantindo que os actores educativos, afectados pelas decisões de política educativa, assumam a dimensão política e cultural da educação, tornando-se "sujeitos de direito" (Sacavino, 2000, p. 45) segundo os ditames da ética da justiça e da ética da solidariedade, reconhecendo ao mesmo tempo que a activação dos seus direitos, como o da autonomia individual, por exemplo, depende da activação simultânea da autonomia cidadã.

Penso que, desse modo, a educação, longe de apoiar, nos tempos de globalização, qualquer Leviatã mundial, pode contribuir, a seu modo, para o projecto de governança democrática global, para globalizar as políticas globais democráticas, para uma globalização humanizadora em que os direitos humanos (da igualdade, da participação, do respeito pela diversidade e da cooperação internacional) se constituam, segundo a representante das Nações Unidas 
para os Direitos Humanos, Robinson (2001), no elemento essencial da sua fundação ética.

Desse modo, a educação contribuirá certamente para a ampliação de uma cidadania terrena e para a expansão do modelo de democracia comunicativa, construída em dialogação e permanentemente aberta a hermenêuticas plurais ou diatópicas que se interpelam continuamente, em conversação, visando a cosmopoliticidade ou a solidariedade cosmopolítica apoiada nos direitos do homem.

Ou seja, e para terminar, os direitos humanos devem constituir-se num modelo para a democracia comunicativa, entendida esta como democracia cosmopolítica, adaptada aos tempos de globalização, cabendo à educação crítica, pela aprendizagem e pela prática de participação, um papel essencial na discussão democrática.

\section{Referências bibliográficas}

APPIAH, K. A. Ciudadanos del mundo. In: GIBNEY, M. J. (Ed.). La globalización de los derechos humanos. Barcelona: Crítica, 2004. p.197-232.

ARENDT, H. A condição humana. Lisboa: Relógio d'Água. 2001.

ARRUDA, M. Globalização e sociedade civil: repensando o cooperativismo no contexto da cidadania activa. In: ARRUDA, M.; BOFF,

L. Globalização: desafios socioeconômicos, éticos e educativos. Petrópolis: Vozes, 2000. p. 49-102.

BEETHAM, D. Democracy and human rights. Cambridge: Polity Press, 2003.

BELTRAN LLAVADOR, F. Hacer pública la escuela. Santiago do Chile: LOM, 2003.

BENAVIDES, M. Educação em direitos humanos: de que se trata?. In R. L. BARBOSA (Org.), Formação de Educadores. Desafios e Perspectivas. S. Paulo: UNESP. 2003, p. 309-318.

BOBBIO, N. Teoria geral da política. São Paulo: Editora Campus, 2000.

BOLTANSKI, L.; CHIAPELLO, E. Le nouvel esprit de capitalisme. Paris: Gallimard, 1999.

BOTLER, A. H. A escola como organização educativa. 2004. Tese (Doutorado) - Universidade Federal de Pernambuco, Recife, 2004.

BOURDIEU, P. L'école conservatrice. L'inégalité sociale devant l'école et devant la culture. Revue Française de Sociologia, v. 3, 1966, p. 325-347.

0 poder simbólico. Lisboa: Difel, 1989.

Escritos de educação. Petrópolis: Vozes, 1998.

CHAMBERLAIN, E.; HOUSTON, B. Políticas contra el acoso sexual en las escuelas: la necesidad de justicia y atención. In: KATZ, M. S.; NODDINGS, N.; STRIKE, K. A. (Orgs.). Justicia y cuidado: en busca de una base ética común en educación. Barcelona: Idea Books, S.A., 2002. p. 169-189.

CORTINA, A. La educación del hombre y del ciudadano. In: Organización de Estados Iberoamericanos para la Educación, la Ciencia y la Cultura (Org.). Educación valores y democracia. Madrid, 1999. p. 49-74.

CROUCH, C. Posdemocracia. Madrid: Taurus, 2004. 
CUNNINGHAM, F. Theories of democracy: a critical introduction. London: Routledge, 2001.

DEROUET, J.-L. École et justice: de l'égalité des chances aux compromis locaux? Paris: Éditions Anne-Marie Métailié, 1992.

ESTÊVÃO, C. V. Justiça complexa e educação: uma reflexão sobra a dialectologia da justiça em educação. Revista Crítica de Ciências Sociais, n. 64, p. 107-134, dez. 2002a.

Globalização, metáforas organizacionais e mudança educacional. Dilemas e desafios. Porto: Edições ASA, 2002b.

. Educação, justiça e democracia. São Paulo: Cortez, 2004.

FITOUSSI, J.-P. ; ROSANVALLON, P. A nova era das desigualdades. Oeiras: Celta Editora, 1997.

GARCÍA-MARZÁ, D. La ética empresarial como ética aplicada: una propuesta de ética empresarial dialógica. In: RUBIO-CARRACEDO, J.; ROSALES, J. M.; MÉNDEZ, M. T. (Orgs.). Retos pendientes en ética y política. Madrid: Trotta, 2002, p. 255-266.

GEORGE, S. Globalización de los derechos? In: GIBNEY, M. (Ed.). La globalización de los derechos humanos. Barcelona: Crítica, 2004. p. 23-38.

GIDDENS, A. As consequências da modernidade. Lisboa: Celta, 1995.

GIMENO, P. Teoría crítica de la educación. Madrid: UNED, 1995.

GREADY, P. Conceptualising globalisation and human rights: boomerangs and borders. International Journal of Human Rights, v. 8, n. 3, p. 345-354, Autumn, 2004.

HABERMAS, J. La inclusión del otro. Barcelona: Piados, 1999.

. Après l'État-Nation. Paris: Fayard, 2000.

IGNATIEFF, M. Los derechos humanos como política e idolatría. Barcelona: Paidos, 2001.

LAFER, C. A reconstrução dos direitos humanos. São Paulo: Companhia das Letras, 1999.

LEVINAS, E. Les droits de l'autre homme. In: COMISSION NATIONALE CONSULTIVE DES DROITS DE L'HOMME. Les droits de I'homme en questions. Paris: La Documentation Française, 1989, p. 43-45.

LUKES, S. Cinco fábulas sobre los derechos humanos. In: SHUTE, S.; HURTLEY, S. (Eds.). De los derechos humanos. Madrid: Trotta, 1998. p. 29-46.

PARKER, M. Against management. Cambridge: Polity Press, 2002.

ROBINSON, M. Humanising globalisation: a role for human rights. 2001. (http://www.globalpolicy.org/globaliz/define/3110.htm)

SABIRÓN. F. Organizaciones escolares. Zaragoza: Mira Editores, 1999.

SACAVINO, S. Educação em direitos humanos e democracia. In: CANDAU, V. M., SACAVINO, S. (Orgs.) Educar em direitos humanos: construir democracia. Rio de Janeiro: DP\&A Editora, 2000. p. 36-48.

SANTOS, B. S. Do pós-moderno ao pós-colonial: e para além de um e outro. In: Congresso Luso-Afro-Brasileiro de Ciências Sociais, 7., Conferência de Abertura. Coimbra, 16 de Setembro de 2004.

SHIVA, V. Derecho a la alimentación, libre comercio y fascismo. In: GIBNEY, M. J. (Ed.). La globalización de los derechos humanos. Barcelona: Crítica, 2004. p. 95-115.

STRIKE, K. A. Justicia, atención y universalidad: en defensa del pluralismo moral. In: KATZ, M. S.; NODDINGS, N.; STRIKE, K. A. Justicia y cuidado: en busca de una base ética común en educación. Barcelona: Idea Books, S.A., 2002a. p. 31-48. 
Tres retratos de la justicia y la atención. In: KATZ, M. S.; NODDINGS, N.; STRIKE, K. A. Justicia y cuidado: en busca de una base ética común en educación. Barcelona: Idea Books, S.A., 2002b. p. 191-202.

YOUNG, I. Intersecting voices. New Jersey: Princeton University Press, 1997.

Recebido em 07.12.04

Aprovado em 13.02 .06

Carlos Alberto Vilar Estêvão é professor associado com agregação do Instituto de Educação e Psicologia da Universidade do Minho, Braga, Portugal. Pertence ao departamento de Sociologia de Educação e Administração Educacional. Tem desenvolvido a sua pesquisa nos campos da "educação e privatização", das "políticas e práticas de formação nas organizações" e da "educação, justiça e democracia". 